\title{
Improving Service Quality Through Strengthening Servant Leadership, Self Efication, and Education Organizational Citizenship Behavior (OCB)
}

\author{
Ismatullah*, Soewarto Hardhienata, Rita Retnowati \\ Pakuan University Bogor, Indonesia
}

*Corresponding Author: Ismatullah, Pakuan University Bogor, Indonesia

\begin{abstract}
Thequality of teacher services is one important aspect that determines the success of achieving educational goals. Teachers who have a high quality of service will be more responsive and empathetic to students, and able to foster comfortable relationships with stakeholders. But unfortunately, the results of an initial survey of teachers in Junior High School in the city of Cilegon have not shown the results as expected, so this is interesting to study. The purpose of this study is to find effective efforts to improve the quality of teacher services by researching related variables, namely serving leadership, self-efficacy and Organizational Citizenship Behavior $(O C B)$. This study uses a design sequential explanatory, using correlational statistical methods to determine whether the leadership variables serving, self-efficacy, and $O C B$ have a positive relationship with the quality of teacher services. SITOREM (Scientific Identification Theory for Operational Research in Education) analysis is used to determine priorities and recommendations for improvements that need to be made. Quantitative research results found that all variables have a significant positive relationship with teacher quality, in order based on the strength of the relationship as follows: self-efficacy (ry2 $=0.626, \rho<0.05)$, leadership serves $(r y 1=0.362, \rho<0.05$ and $O C B(r y 3=0.316 \rho$ $<0.05)$. Consistent with the results of quantitative analysis, the results of qualitative data analysis also show that the quality of service can be improved through increasing leadership in serving, self-efficacy and OCB. SITOREM analysis results show that the components of service quality, service leadership, self-efficacy and OCB of teachers who need improvement are: 1) task complexity, 2) task challenges, 3) emotional healing, 4) altruism, 5) conscientiousness, 6) civic virtue, 7) sportsmanship, 8) reliability, 9) assurance, and 10) tangibles.
\end{abstract}

Key words: servant leadership, self-efficacy, Organizational Citizenship Behavior, teacher service quality, SITOREM

\section{INTRODUCTION}

Good quality education, capable of producing quality human resources, achievement and creative and highly competitive. To be able to improve human resources through the education sector, the good school management is needed to improve the quality of education itself, one of the indicators is the level of service of educational institutions to students in particular, as subjects and objects in learning.

Improving the quality of teacher services must be a concern of teachers in schools today, especially in the future. The teacher has a position as a professional who is appointed in accordance with statutory regulations - recognition of the position of the teacher as a professional, proven by an educator certificate. As a professional, it means that teachers are required to have expertise, skills or skills that meet certain quality standards or norms and require professional education for educators.

This can be seen from the results of observations and preliminary research conducted on 30 teachers in State Junior High Schools in the City of Cilegon, Banten Province on 7-9 May 2018, through a questionnaire instrument, the fact that there is still a percentage of the quality of teacher services not as expected especially on the indicators as follows:

1. $51.67 \%$ on indicators of physical appearance and service facilities;

2. $63.33 \%$ on indicators of reliability and diversity in services;

3. $53.30 \%$ on indicators guarantee confidence in services;

4. $66.67 \%$ on indicators of rapid response in services; 


\section{5. $65.00 \%$ on indicators of concern and attention.}

Based on the explanation above, it can be explained that it is very important to improve the quality of teacher services so that the image of the school where the teacher teaches is better. The quality of education where the school stands is increasing and steady following the vision of the City of Cilegon. Besides, the quality of teacher services will have an impact on overall school quality. Related to the importance of the quality of teacher services, this dissertation will describe research on the quality of teacher services, particularly the quality of service of teachers in state junior high schools in the city of Cilegon.

Quality of service of civil servant teachers in Secondary Schools in Cilegon, allegedly much influenced by various factors, including servant leadership of principals, self-efficacy of teachers and organizational citizenship behaviorof teacher, organizational culture, organizational climate, performance, system, reward and punishment supervision, headmaster leadership factors, work commitment and others.

Servant leadership of the principal can give high confidence to the teachers. Principals who prioritize excellent service always pay attention to the needs of others by providing a variety of needs that can support the quality of work and services of teachers, students, and administrative staff, especially in the availability of visible facilities. Another factor that is thought to have a relationship with the quality of teacher services is self-efficacy, namely the confidence that grows in a person so that he can perform professional tasks given with a certain level of success. Teachers who have confidence in success tend to be more motivated to learn and improve their competence seriously. Really in carrying out work or learning tasks.

Conversely, teachers with low self-efficacy tend to be hesitant to develop their competencies, lack the courage to try new things, reduce their participation in group discussions, so that learning opportunities between fellow teachers are reduced. Low teacher self-efficacy inhibits the teacher's contribution to innovate and result in a lack of quality teacher services. Besides, the Organizational Citizenship Behavior (OCB) is the voluntary behavior of the teacher to educate beyond the standards set by the school following the minimum service standards that must be met.

Based on the background that has been described, the formulation of the problems in this study are as follows:

1. Is there a relationship between the principal's servant leadership and the quality of teacher services?

2. Is there a relationship between self-efficacy and the quality of teacher services?

3. Is there a relationship between organizational citizenship behavior (OCB)and the quality of teacher services?

4. Is there a relationship between the principal's servant leadership and teacher selfefficacy,organizational citizenship behavior (OCB) of teachers, together with the quality of service of teachers?

\section{LITERATURE REVIEW}

\subsection{Quality of Service}

Harris (2011), in his research, suggests that the quality of service is a comparison between the quality of services received after receiving the expected quality. The indicators are 1. Reliability, consistent in providing services, 2. Responsiveness, responsiveness in providing services, 3. Assurance, guarantee in providing services, 4. Empathy, careful attention to user needs, 5. Tangibles, infrastructure facilities and service facilities provided.

In line with this, Boyd (2011) argues that service quality is an effort that can be used to analyze gaps that occur in the service quality performance of an organization with the needs of the quality of user services. As for the indicators are 1. Tangibles, (physical appearance), with regard to the physical appearance of service facilities, equipment or equipment, and corporate human resources, 2. Responsivenessregarding the willingness and ability of service providers to respond to their requests immediately, 3. Assurance (guarantee of trust), with regard to the ability to foster consumer trust and 
confidence, 4. Empathy (attention to consumers) provides personal attention to users, 5: reliabilityorganizations to deliver the promised service accurately and quickly.

\subsection{Servant Leadership}

Orphanos (2014) suggests that servant leadership theory is based on service to others and the recognition that the role of organizations is to create people who are able to build a better future, experts, practitioners who respond to perceptions that develop where its characteristics are: 1listening, 2. Empathy, 3. Recovery, 4. Self-awareness, 5. Persuasion, 6. Conceptualization, 7. Foresight, 8. Arranging services, 9. Commitment to trust, 10. It is building a community in maintaining wholeness.

According to Shek (2015), it is argued that servant leadership focuses on the role of the leader in his relationship with followers, built through the allocation of opportunities for followers to help him grow and develop. Its characteristics are 1. Empowerment, empowerment of motivation, 2. Accountability, control and responsibility actions, 3. Standing back, prioritizing the interests of others, 4. Humility, putting achievements and talents in the right perspective, 5. Authenticity, the true state, 6 . Courage, dare to take a new approach in a proactive, innovative and creative manner, 7. Interpersonal acceptance, understanding feelings and alleviating problems, 8.Stewardship, willingness to take responsibility.

Based on the theoretical study above, it can be synthesized that servant leadership is the behavior of leaders who focus on managing the organization for career development and services so as to create a conducive climate for work and make changes for the progress of the organization they lead. The indicators of servant leadershipcan be synthesized from a variety of theories above, including 1.attentively (listening), 2. Trying to understand (strives to understand), 3. Efforts to restore emotional relationships (emotional healing ),4. Self-awareness, 5. The ability to influence others (persuasive mapping), 6. Thinking Conceptualization perspective (conceptualization), 7. Outlook for the future (foresight), 8. Structuring services to the organization (organizational stewardship), 9. commitment to personal growth (commitment to the growth of people),10. Establish community motivation(community-building).

\subsection{The Self-Efficacy}

Mojo Vezi (2012) argues that the teacher's self-efficacy is a person's beliefs about his ability to organize and take action needed to complete tasks and be able to influence choices in action, the amount of effort done and the level of business persistence in the form of motivation or enthusiasm. There are four characteristics of the determinants that affect the level of one's self-efficacy, namely: 1 . Previous performance experience, 2. Learning from experience, 3. Verbal persuasion, meaningful messages, and 4. Controlled emotional state.

According to Viel (2010), self-efficacy is the confidence that a person has to work well in certain situations. Its characteristics are 1: magnitude, the magnitude of the task level, 2. Strength, holding on to the strength of belief, 3. Generality, the extent to which expectations are generalized in all situations and conditions.

Based on some theoretical studies above, it can be synthesized that self-efficacy is an individual's belief in his ability to organize, work, and complete tasks according to their responsibilities with a certain level of success so as to give good results. These successes include organizing, doing and completing tasks according to their responsibilities with a certain level of success so that it gives the best results because it is influenced by the experience possessed and forms a strong personality and is tested by various obstacles that occur, situations and conditions that shape increasingly become a reality.

\subsection{Organizational Citizenship Behavior (OCB)}

The formulation of OCB is delivered by Chiang (2012) which states that OCB is a personality with certain traits and characteristics found in a person by always working together, happy to help, caring for others, and fullness in working. The characteristics of OCB, according to Luthans, are 1. Altruism is the behavior of helping coworkers if there is an obstacle, 2. Conscientiousness, which is always working hard and completing work with full responsibility, 3. Civic Virtue, namely carrying out 
community activities with volunteering (volunteering) to improve the image of the organization, 4.Sportsmanship, is an attitude that grows by itself, participate feeling guilty and responsible, and 5. Courtesy, namely mutual understanding and feeling behavior(empathy) over the difficulties of the work environment.

Based on some theoretical studies above, it can be synthesized that OCB is a positive action someone outside of their obligations which is carried out extra, effectively, and voluntarily to support the operation of the organization. Indicators from OCB can be concluded: 1. Altruism, namely voluntary behavior in helping colleagues who have difficulties so that work problems can be resolved properly, 2.Conscientiousness), namely the seriousness of working behavior of employees who have the high dedication and always work hard even over standard, 3.Civic virtue, which is wise behavior full of responsibilities of employees so that users are satisfied, 4.Sportsmanship, which is a tolerance behavior that is done to the situation that is not ideal, without complaining, by maintaining organizational performance, and 5. Courtesy, namely the behavior of respecting staff who focus on alleviating work-related problems.

\section{METHODS}

This study was conducted on state junior high school teachers in the city of Cilegon, Banten province, from February to August 2019. The method used in this study is combination research sequential explanatory, which combines quantitative and qualitative research methods in a sequentially, where in the first stage the study was conducted using quantitative methods and in the second stage was carried out with qualitative methods. The research variables consisted of three independent variables namely servant leadership $\left(X_{1}\right)$, self-efficacy $\left(X_{2}\right)$, organizational citizenship behavior $\left(\mathrm{X}_{3}\right)$ with the dependent variable namely the quality of teacher services $(\mathrm{Y})$.

Data collection techniques in qualitative research, conducted in natural settings (conditions), primary data sources, more data on observation, (in-depth interviews, documentation studies, and focus group discussions (FGD).

After that, the data continued with the implementation phase analysis and discussion of the results of quantitative and qualitative research methods of SITOREM (Soewarto Hardhienata, 2007). Based on the analysis of quantitative and qualitative research through SITOREMmethod, it can be drawn conclusions and implications of the research results. From the conclusions and implications can be determined suggestions and action plan as a final result from this research, mixed methods SITOREM analysis is used to identify the strength of the relationship between the independent variable and the dependent variable and to analyze the conditions of the indicators of each research variable, and to analyze the weight of each indicator of each research variable based on the material cost, benefit, urgent, importance. Based on the results of the analysis of the above relationship, the information will be obtained about which indicators need to be improved or improved immediately, and which ones need to be maintained or developed.

\section{RESUltS AND DisCUSSION}

\subsection{Relationship Between Principal' Servant leadership With Teacher Service Quality}

Based on the results of hypothesis testing the functional relationship between principal's servant leadership with teacher service quality shows the correlation coefficient $r_{y 1}=0.362$ with a coefficient of determination $r_{y 1}=0.1308$. This means that $13.08 \%$ of the quality of teacher services is the work of leadership variables of servant leadership of the principal. In comparison, $86.92 \%$ is contributed by other variables that have a relationship with improving the quality of teacher services. In other words, the relationship between principals' servant leadership with teacher service quality is not significantly influenced by the teacher's self-efficacy variable and variable organizational citizenship behavior.

The results obtained from these two stages can be seen that servant leadership is giving power that aims to encourage teachers to take part in the role of the principal following their competencies, with leadership expected to be able to make teachers more creative, and can work according to their abilities, teachers are more confident in carrying out the tasks assigned to them without pressure from the school principal, this can contribute to improving the quality of teacher services. This is in line with the theory put forward by Paris (2013) that leaders who serve prioritize service, starting with desire from within himself who wants to serve and always put service for others. Furthermore, consciously, this choice brings aspirations and encouragement in leading others. 
This finding is consistent with the results of previous studies conducted by Paris (2013) which concluded that the influence of servant leadershipon service quality is very strong, there is a significant positive relationship $(r=0.66, \rho<0.001)$ between indicators of servant leadershipwith the quality of teacher services in schools. The higher the level of servant leadership, it is predicted that the higher the level of quality of service of the teacher in the school.

The quantitative data above is reinforced by qualitative observational data. It can be concluded that the condition of servant leadership of principals in each school that was observed has been implemented, the teacher feels valued the results of his work, so that servant leadership of principals in the field has the same tendencies with servant leadership of principals qualitatively. Based on this explanation, it can be concluded that the better the leadership, the better the quality of teacher services at the school. Factual findings and data in the analysis of this study further support previous findings regarding the positive relationship between servant leadership of principal and the quality of teacher services.

\subsection{Self-Efficacy Relationship Between Teacher with Quality of Service}

Strength of the relationship between self-efficacy of teachers with teachers' quality of service is shown by the correlation coefficient $r_{\mathrm{y} 2}$ of 0.626 with the coefficient of determination $\mathrm{R}_{\mathrm{y} 2}$ at 0.3916 . This means that $39.16 \%$ of the quality of teacher services is motivated by the teacher's self-efficacy of teachers. In comparison, $70.84 \%$ is contributed by other variables that have a relationship with service quality. Based on this description, it can be concluded that the regression is significant, and shows that any increase in the teacher's self-efficacy score will also improve the quality of service. Facts and data findings in the analysis of this study further support previous findings regarding the existence of a significant relationship between teacher self-efficacy and service quality.

The results obtained from these two stages can be seen that the teacher's self-efficacy is a desire to exceed a set standard and strive for success, the teacher's self-efficacy can make teachers more creative and innovative in carrying out their duties, the teacher always wants to do more good and always want to learn and excel to improve competence, this can contribute to improving the quality of teacher services.

The results of this study are in line with the results of Calik's (2012) study which concluded that there was a significant positive relationship $(r=0.23 \mathrm{p}<0.05)$ between self-efficacy and service quality. The higher the level of self-efficacy, it is predicted that the higher the level of service quality of teachers in schools. The quantitative data above is strengthened by qualitative observational data showing that the better the self-efficacy, the better the quality of teacher services will be (Rajiani,2010).

\subsection{Relationship Between Organizational Citizenship Behavior and the Quality of Teacher Services.}

The strength of the relationship between organizational citizenship behavior with the quality of teacher services is shown by the correlation coefficient $r_{y 3}$ of 0.316 with the coefficient of determination $\mathrm{R}_{\mathrm{y} 3}=0.1001$. This means that $10.01 \%$ of the quality of teacher services is the result of teachers' commitment to the organization, while $89.99 \%$ is contributed by other variables that have a relationship with improving the quality of teacher services.

The partial correlation coefficient of Organizational citizenship behavior with the leadership variable controlling the principal serves $r_{\mathrm{y} 31}=0.3009$, and the teacher's self-efficacy variable is $r_{\mathrm{y} 32}=0.198$. From the two partial correlation tests, it can be concluded that the relationship of organizational citizenship behavior with the quality of teacher services is very significant at a level $=0.05$, with the quality of teacher services and teacher self-efficacy variables. In other words, the relationship between organizational citizenship behavior with the quality of teacher services is not significantly affected by the leadership variable serving the principal and the teacher's self-efficacy variable.

The quantitative data above is strengthened by the qualitative observational data it can be concluded that organizational citizenship behavior with the quality of teacher services in each School that is observed has the same character pattern in accordance with the characteristics of the environment. 
The findings obtained from 2 of these studies explain that organizational citizenship behavior is a positive action taken by someone effectively and efficiently as an attitude of teacher loyalty in engaging with School and willing to sacrifice and devote himself to advancing School voluntarily to the desired goals, increasingly the higher attachment, loyalty, desire, ownership, contribution, and teacher involvement, the higher organizational citizenship behavior. If teachers have high organizational citizenship behavior, the quality of teacher services will be more optimal. This result is in line with OCB's formulation, according to Ostrof (2012), which states that OCB is individual behavior that provides progress towards the organization and works beyond the responsibilities it imposes (Rajiani, 2011) .

The findings of this study support previous research conducted by Arifin (2015) which proves that there is a significant positive relationship $(r=0.33, \rho<0.05)$ between indicators of organizational citizenship behavior(OCB) and service quality. The higher the OCB level of teachers, it is predicted that the higher the quality of teacher services in schools. The higher the organizational citizenship behavior(OCB) attitude towards the organization is predicted, the higher the level of quality of teacher services.

Based on this description, it can be concluded that the higher the organizational citizenship behavior, the higher the quality of service. Thus the findings of facts and data in the analysis of this study further support previous findings regarding the existence of a significant relationship between organizational citizenship behavior with the quality of teacher services.

\subsection{Relationship Between Servant Leadership, Teacher's Self-Efficacy and Organizational Citizenship Behavior Together with the Quality of Teacher Services.}

The results showed that there was a positive relationship between leadership serving the principal, teacher's self-efficacy and organizational citizenship behavior together with service quality. This is indicated by the correlation coefficient $\left(\mathrm{r}_{\mathrm{y} 123}\right)$ of 0.968 . Classified as very strong and declared very significant. With the coefficient of determination $\mathrm{R}_{\mathrm{y} 123}=0.937$, it means that $93.7 \%$ of the quality of teacher services is the work of leadership serving the principal, teacher's self-efficacy, and organizational citizenship behavior together. In comparison, $6.3 \%$ is contributed by other variables which have to do with the quality of teacher services.

Leadership serves the principal in conducting his activities prioritizing humility, being honest, and always expressing himself consistently in his leadership as a form of commitment to himself to prioritize the interests of others. In contrast, the teacher's self-efficacy that grows and develops in a person can affect his perception, motivation, and performance. The teacher's self-efficacy refers to the individual's beliefs about his ability to achieve success according to his responsibilities in achieving success in certain situations.

As for other factors related to service quality, based on the results of interviews and FGD on qualitative research, it can be seen that in addition to the variables of leadership serving school principals, teacher self-efficacy, and organizational citizenship behavior there are other factors that affect service quality, such as emotional intelligence, transformational leadership, teacher job satisfaction, organizational culture, teacher performance.

Based on the results of hypothesis testing, it is proven that all three hypotheses proposed can be accepted significantly. Overall this study shows there is a positive relationship between 1) Servantleadership of principals with the quality of teacher services, 2) Self-efficacy of teachers with the quality of teacher services, 3) Organizational citizenship behavior with quality of teacher services, 4) Servant leadership of principals and self-efficacy teachers together with the quality of teacher services, 5) Servant leadership of principals and organizational citizenship behavior together with the quality of teacher services, 6) teacher self-efficacy and organizational citizenship behavior together with service quality, 7) Servant leadership of principals, teacher self-efficacy and organizational citizenship behavior together with the quality of teacher services. 


\subsection{Sitorem Analysis}

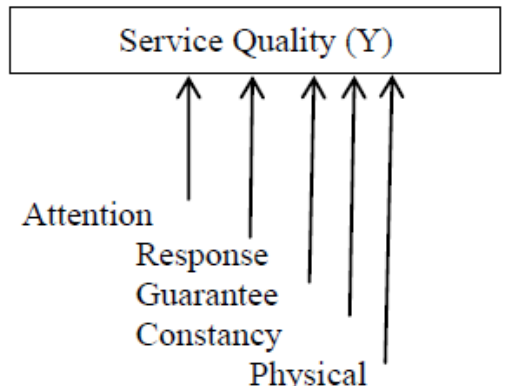

Physical
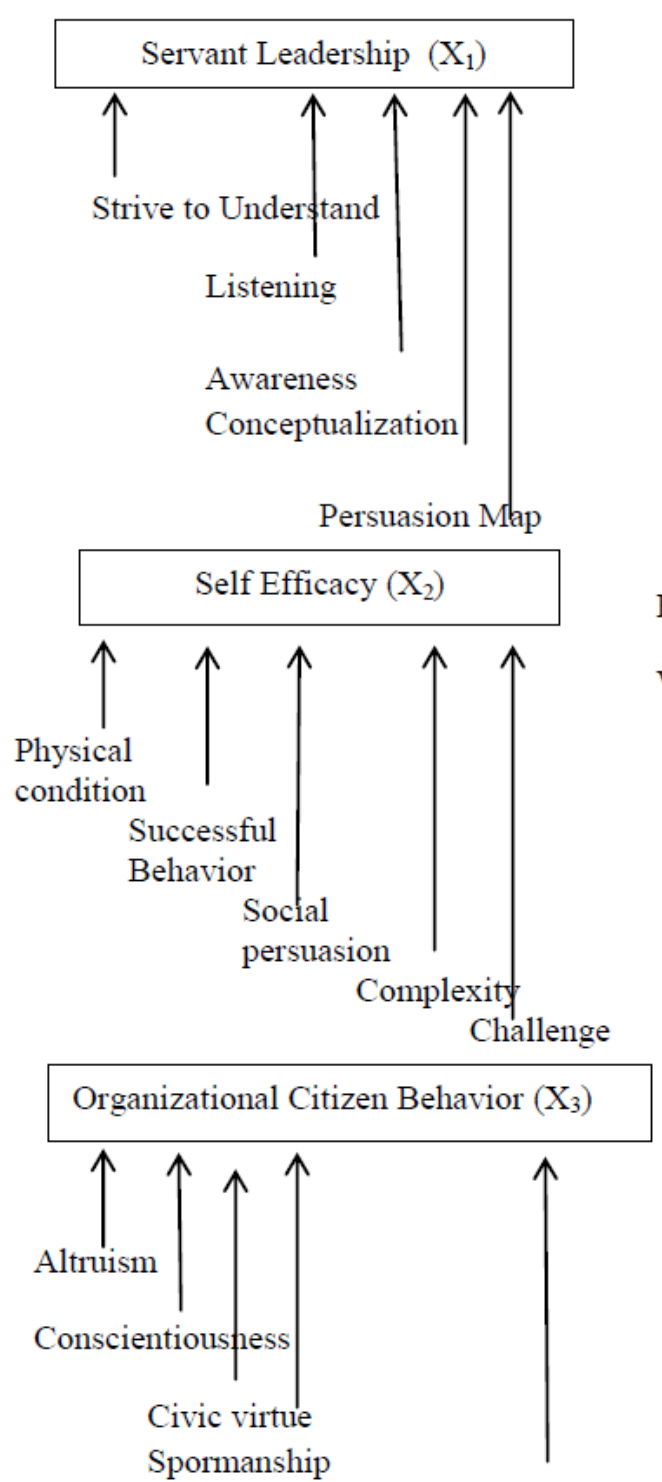

Courtesy

\section{WEIGHING AND INDICATOR SCORES}

1. Attention $(24,32 \%),(4,26)$

2. Response $(21,62)(4,03)$

3. Guarantee $(18,92 \%),(3,79)$

4. Constancy $(18,92 \%),(3,74)$

5. Physical $(16,22 \%)(3,29)$
$R=0.362$

\section{WEIGHING AND INDICATOR SCORES}

1. Strive to Understand $(13,43 \%)(4,05)$

2. Listening $(11,94 \%)(4,07)$

3. Awareness $(10,45 \%)(4,53)$

4. Conceptualization $(10,45 \%)(4,32)$

5. Persuasion Map $(8,96 \%)(4,67)$

$\mathrm{R}=0.626$

\section{WEIGHING AND INDICATOR SCORES}

1. Physical condition $(13,85 \%),(4,34)$

2. Successful Behavior $(12,31 \%),(4,34)$

3. Social persuasion $(12,31 \%)(4,36)$

4. Complexity $(12,31 \%)(3,72)$

5. Challenge $(10,77 \%)(3,85)$

$\mathrm{R}=0.316$

\section{WEIGHING AND INDICATOR SCORES}

1. Altruism $(24,05 \%)(3,28)$

2. Conscientiousness $(22,78 \%)(3,97)$

3. Civic virtue $(20,25 \%)(3,81)$

4. Spormanship $(17,72 \%)(3,81)$

5. Courtesy $(15,19 \%)(4,64)$

Figure1. Analysis of SITOREM (Scientific Identification Theory for Operational Research in Education)

\section{CONCLUSION}

1. There is a positive and very significant relationship between servant leadership of principals with the quality of teacher services by $13.8 \%$. The results of qualitative research indicate a tendency for relationships that are aligned with quantitative data between servant leadership and service quality. The higher the value ofservant leadership, the better the quality of teacher services, and vice versa. SITOREM analysis shows indicator that need to be improved is emotional healing. 
2. There is a very significant positive relationship between self-efficacy and the quality of teacher services by $39.16 \%$. The results of qualitative research indicate a tendency for the relationship to be in harmony with quantitative data between self-efficacy and service quality. The higher the value of self-efficacy, the quality of teacher services will be better, and vice versa. SITOREM analysis states that there are two indicators, namely task complexity and task challenges that must be corrected.

3. There is a positive and very significant relationship between OCB and the quality of teacher services by $10.1 \%$. The results of qualitative research indicate a tendency for relationships that are in harmony with quantitative data between OCB and service quality. The higher the value of $\mathrm{OCB}$, the better the quality of teacher services, and vice versa.

4. There is a positive and very significant relationship between leadership serving school principals, teacher self-efficacy and teacher organizational citizenship behaviortogether with the quality of teacher services by $93.7 \%$.

\section{BIBLIOGRAPHY}

[1] Arifin, HM (2015). The Influence of Competence, Motivation, and Organizational Culture to High School Teacher Job Satisfaction and Performance. International Education Studies, 8(1), 38-45.

[2] Boyd, D., Lankford, H., Loeb, S., Ronfeldt, M., \& Wyckoff, J. (2011). The role of teacher quality in retention and hiring: Using applications to transfer to uncover preferences of teachers and schools. Journal of Policy Analysis and Management, 30(1), 88-110.

[3] Calik, T., Sezgin, F., Kavgaci, H., \& Cagatay Kilinc, A. (2012). Examination of Relationships between Instructional Leadership of School Principals and Self-Efficacy of Teachers and Collective Teacher Efficacy. Educational Sciences: Theory and Practice, 12(4), 2498-2504.

[4] Chiang, CF, \& Hsieh, TS (2012). The effects of perceived organizational support and psychological empowerment on job performance: The mediating effects of organizational citizenship behavior. International journal of hospitality management, 31(1), 180-190.

[5] Harris, DN, \& Sass, TR (2011). Teacher training, teacher quality and student achievement. Journal of public economics, 95(7-8), 798-812.

[6] Mojavezi, A., \& Tamiz, MP (2012). The Impact of Teacher Self-efficacy on the Students' Motivation and Achievement. Theory \& Practice in Language Studies, 2(3).

[7] Orphanos, S., \& Orr, MT (2014). Learning leadership matters: The influence of innovative school leadership preparation on teachers' experiences and outcomes. Educational Management Administration \& Leadership, 42(5), 680-700.

[8] Ostroff, C., Kinicki, AJ, \& Muhammad, RS (2012). Organizational culture and climate. Handbook of Psychology, Second Edition, 12.

[9] Parris, DL, \& Peachey, JW (2013). A systematic literature review of servant leadership theory in organizational contexts. Journal of business ethics, 113(3), 377-393.

[10] Rajiani, I., \& Jumbri, I. A. (2011). The cultural ecology of new public management in Indonesia. Journal of Administrative Science, 8(1), 17-31.

[11] Rajiani, I. (2010). Applying Personality Traits to Predict Loyalty and Neglect among Employees of Bank Jatim Located in 10 Big Cities of East Java (Mc Crae's and Hofstede's Theories on the effect of Culture on Personality Revisited). Jurnal Aplikasi Manajemen, 8(3), 617-622

[12] Shek, DT, Yu, L., \& Siu, AM (2015). Interpersonal competence and service leadership. International Journal on Disability and Human Development, 14(3), 265-274.

[13] Viel-Ruma, K., Houchins, D., Jolivette, K., \& Benson, G. (2010). Efficacy beliefs of special educators: The relationships among collective efficacy, teacher self-efficacy, and job satisfaction. Teacher Education and Special Education, 33(3), 225-233.

Citation: Ismatullah, et.al. "Improving Service Quality Through Strengthening Servant Leadership, Self Efication, and Education Organizational Citizenship Behavior (OCB)" International Journal of Managerial Studies and Research (IJMSR), vol 8, no. 7, 2020, pp. 64-71. doi: http:// dx.doi.org/10.20431/23490349.0807008 .

Copyright: (C) 2020 Authors. This is an open-access article distributed under the terms of the Creative Commons Attribution License, which permits unrestricted use, distribution, and reproduction in any medium, provided the original author and source are credited. 